\title{
Editorial
}

\section{Realidad en su número cien}

Al publicar la centésima edición de nuestra revista Realidad, queremos recordar que estos cien primeros números, y los que les precedieron con otro nombre, nacen de un pensamiento común: "el quehacer universitario es cultivar la realidad para transformarla". La realidad es la maestra de la vida que plantea preguntas y obliga a dar respuestas, en la conciencia de que "otro mundo mejor es posible". Lo que bemos querido hacer es pasar de la protesta a la propuesta alternativa, de acuerdo al lema de la UCA: "ser conciencia critica y constructiva de la realidad nacional".

Tuvimos la suerte, o la responsabilidad, de que la UCA nació en un tiempo de inconformidad y de buisqueda nacional y mundial (1965-1966), entre diversas opciones y preocupaciones marcadas por la conflictividad. En el ámbito mundial, era el tiempo de la "guerra fría", tipificado por la carrera armamentística entre sistemas que se miraban como enemigos irreconciliables, aunque también existian quienes afirmaban: 'en teoría, no puedo identificarme ni con uno ni con otro sistema'. La realidad era un mundo crucificado en el enfrentamiento entre el Este y el Oeste y el Norte y el Sur. Dentro de nuestro istmo no era tarea fácil conciliar los cuatro 
cuadrantes, cuando a las ideas se les respondía pronto con el argumento de las bombas. Son años de inconformidad $y$ de buisqueda.

Junto a los enfrentamientos ideológicos de los sistemas económicos $y$ las medidas de represión, se inicia un movimiento de preocupación $y$ de búsqueda dentro de la Iglesia, en singular o en plural. El Concilio Vaticano II anuncia la misión de "la Iglesia en el mundo de boy": llevar la buena noticia del Sermón de la Bienaventuranzas a los pobres del mundo. Se hablará de 'inspiración cristiana'. Hechos, abora olvidados, tuvieron entonces un gran impacto. El Papa Pablo VI publica la encíclica El desarrollo de los pueblos, en 1967, entendiendo que el pueblo es tanto más pueblo cuanto más lejos está del capital y de la capital. Lo temible de esta encíclica es que planteaba, a nivel del tercer mundo, los temas tabues de la reforma agraria, estructuras fiscales más equitativas $y$, sobre todo, la necesidad de corregir las relaciones asimétricas Norte-Sur. Por lo que atañe a América Latina, estos problemas sociales, éticos y bumanos se reflexionan y se traducen en una nueva evangelización en las Conferencias Episcopales de Medellín (Colombia) y Puebla (México), que también generan serias tensiones dentro del rebaño cristiano.

La preocupación por el desarrollo nace de la conciencia del "desarrollo del subdesarrollo", anverso y reverso de la misma realidad. En el contexto de América Latina tuvimos una buena idea, aunque no le atinamos en la realización. El bemisferio Norte era un sólido mosaico de tres grandes bloques, medio amigos $y$ medio enemigos: el Mercado Común de los Estados Unidos, el Mercado Común Europeo, y el COMECON, llamado también $C A E M$, que aglutinaba las economias del bloque soviético. La carrera armamentistica se complementaba con la competitividad económica. Los países del Norte, ¿son fuertes porque se unen, o se unen porque son fuertes? Asi nace, entre otras experiencias latinoamericanas, nuestro Mercado Común Centroamericano. Esta era una nueva realidad, una alternativa económica que debiamos analizar. Con dolor y frustración volvemos a recordar que no fue 
la "guerra del fútbol", sino las competencias empresariales el origen de la guerra entre Honduras y El Salvador, en 1969, con el despojo $y$ doble destierro de miles de pobres campesinos salvadoreños refugiados en el interior de Honduras. Esta era la triste realidad nacional a fines de los años sesenta, que, a su vez, plantea nueva realidades.

La nueva Asamblea Legislativa convocó al Congreso Nacional de la Reforma Agraria, a finales de 1969, actividad en la que participó la UCA, porque habia que dar una respuesta racional y bumana antes de que el volcán explotara. En el primer día de la convocatoria se retiran bruscamente los representantes del sector privado y la reforma agraria se convierte en uno de los puntos más candentes de la realidad nacional. En esos años, viviamos una realidad doblemente quebrada. La "guerra de las cien horas" quebró durante diez años, el Mercado Común Centroamericano, al mismo tiempo que el Congreso Nacional de la Reforma Agraria mostraba la creciente polarización interna, que se traduce en la gestación de grupos populares inconformes $y$ organizados para la confrontación política, incluso armada.

También dentro de nuestra realidad aparecen propuestas de alternativas económicas. Imitando, más bien, a Europa Occidental, desde 1968 se da inicio a los Planes de Desarrollo Económico y Social, en dos quinquenios consecutivos (MIPLAN), en busca de un crecimiento armónico de todos los sectores productivos. Para ello era necesario presentar la difícil realidad económica y plantear medidas alternativas, entre ellas la reforma agraria, fiscal, el papel del Estado en la conducción de la economía, por ser años de grandes inversiones públicas. Enseguida se verá que la palabra "plan y planificación" no estaba en el diccionario de los grupos más poderosos. También esto era parte de la realidad nacional. Por añadidura -y abora lo entendemos- en 1973 estalla el 'choque petrolero' cuando los miembros de la Organización de Países Exportadores de Petróleo (OPEP) cuadruplican el precio del crudo, dando inicio a un fuerte proceso de inflación, que golpea aún más 
los magros ingresos de las clases populares. Nuestra realidad nacional corria demasiado aprisa y no daba tiempo a escribir su bistoria.

Algo babia que decir y algo babia que hacer para transformar esta realidad. Para poder decir y para poder sugerir se debian editar más revistas, y para hacerlo, era necesario tener una imprenta y una editorial. Ya nos babía sucedido que cuando dependíamos de imprentas externas nos retrasaban la edición y las propuestas se convertian en inventarios de bodega. Entonces, comenzó la guerra contra las revistas y contra nuestra naciente imprenta. Por abi comenzó la primera y por abi terminó la última de las veintiocho bombas que nos estallaron dentro de la UCA. Por eso, decimos que cultivar la realidad cuesta caro. Ello llevó un largo tiempo: el periodo comprendido entre 1975 y 1989.

En la década de 1970 comenzamos con un sencillo periódico de temas económicos, respondiendo al ideario plasmado en la obra de Román Mayorga, La universidad para el cambio social (UCA Editores, 1976), que describe el itinerario de la primera década de nuestra universidad. En 1977 editamos el Boletín de Ciencias Económicas y Sociales, respondiendo a la doble función de presentar a nuestros alumnos la realidad nacional y de proyectar fuera de la UCA nuestras propuestas alternativas para el cambio social. No eran tiempos fáciles para las revistas de la UCA, especialmente para ECA (Estudios Centroamericanos). Muchos recuerdan que el editorial titulado " $A$ sus órdenes mi capital", luego de la 'marcha atrás' que el general Molina diera a la "Transformación Agraria", nos costó un sonoro bombazo en la Administración Central. Un botón de muestra de la conflictividad de esos años ba quedado plasmado en la obra El Salvador, entre el terror y la esperanza (UCA Editores, 1982), que recoge las breves noticias y comentarios emitidos en la YSAX (dos veces bombardeada), la Voz Panamericana de Monseñor Romero. Tiempos inolvidables que se traducen en el insensato e impune asesinato de Monseñor Romero. $Y$ después viene la guerra, la década destructiva. 
En 1989 damos un salto cuantitativo y cualitativo con la edición de Realidad Económica y Social, con el formato de una revista bimensual de unas 150 páginas y un papel de mejor calidad. El Boletin tenía cada vez mayor aceptación dentro y fuera de la UCA $y$ creímos necesario transformarlo en una revista de los Departamentos de Economía, Sociología y Ciencias Politicas, que diera espacio a artículos más amplios de nuestros profesores. El Consejo de Redacción evalúa la calidad académica de los artículos, abiertos siempre al abanico de pensamientos de los distintos autores. Como la realidad es multiforme y multilateral, recortamos el título de la revista para ampliar el número de colaboradores y en 1994 se edita como Realidad, Revista de los Departamentos de Ciencias Sociales y Humanidades. Con el desarrollo de las Maestrias, la UCA se beneficia del flujo de profesores internos y visitantes, académicos provenientes de reconocidas universidades, que en la pasada década nos han ayudado a descubrir una realidad multifacética, que se enriquece con los aportes de una filosofía humanista.

Con los acuerdos de paz, la realidad adquiere un nuevo carácter de conflictividad porque, descompuestos los 'socialismos reales', se impone el 'pensamiento único'. Con 'el fin de la historia', no queda otra alternativa. El nuevo imperio se llama "Consenso de Washington", una matriz universal ideada por el consenso de unos pocos, una globalización que es más lo que excluye que lo que incluye. Franz Hinkelammert plantea con acierto que "el proceso de la globalización pasa desde hace dos décadas por encima de América Latina, así como pasa por encima del mundo entero, como un buracán. La privatización de Las funciones del Estado, el libre comercio, el desencadenamiento de los movimientos internacionales de los capitales, la disolución del Estado social, la entrega de las funciones de planificación económica a las empresas multinacionales y la entrega de la fuerza de trabajo y de la naturaleza a las fuerzas del mercado ban arrollado el continente".

El nuevo imperio se convierte en imperialismo cuando algunos gobiernos latinoamericanos lo aceptan, con fe ciega, como la panacea 
que nos lleva al progreso, a la democracia y a la libertad de los pueblos. Gobiernos, Bancos Centrales, sectores privados y ciertos institutos de investigación, cuentan con el oligopolio de los medios de comunicación social, donde la gran ausente es la autocritica. Aunque no somos los únicos, gracias a Dios, nuestra revista actualiza su tarea de ser conciencia crítica y constructiva de la realidad nacional. La historia nos va dando la razón porque cada vez crece más la esperanza de otra alternativa. Nuestra mision es alimentar esa esperanza porque la globalización neoliberal está en crisis económica, en crisis moral y espiritual y en crisis de seguridad. Durante cuatro foros sociales mundiales (Porto Alegre y Bombay) se ha dicho: "otro mundo es posible", y en el foro económico mundial de Davos celebrado en 2004 se ha dicho que "el eje del mal es la pobreza, el sida y la guerra".

Si éste no puede ser el fin de la historia, żqué bacer con la bistoria? También en la citada reunión de Davos se ha dicho que el desafío mundial requiere integrar estos tres objetivos claves: "cooperación, seguridad y prosperidad". Vivimos en un mundo donde "no es posible la seguridad sin la prosperidad, ni la prosperidad sin la seguridad; ambos objetivos son inseparables. Igualmente, los problemas globales no pueden resolverse mas que de una manera global, es decir, incluyendo a todos los sectores claves en la buisqueda de soluciones. De abi la idea simple de la inseparabilidad de las tres nociones. La ausencia de uno de los tres ingredientes compromete la misma idea de progreso". Parecería que entre Davos y Porto Alegre se nos devuelve la esperanza y se nos actualiza de tarea de analizar la realidad para transformarla $y$ lograr la "seguridad bumana" de todos. 